\title{
A Case Report of Isolated Left Ventricular Non-Compaction Presenting with Congestive Heart Failure and Intramural Thrombus
}

\author{
Laxmi Narayan Goit ${ }^{*}$, Shaning Yang² \\ ${ }^{1}$ Department of Cardiology, The First Affiliated Hospital of Yangtze University, Jingzhou, China \\ ${ }^{2}$ Department of Cardiology, Clinical College of Yangtze University and The First Affiliated Hospital to Yangtze University, \\ Jingzhou, China \\ Email: *laxmi_goit@hotmail.com, 1966157381@qq.com
}

How to cite this paper: Goit, L.N. and Yang, S.N. (2019) A Case Report of Isolated Left Ventricular Non-Compaction Presenting with Congestive Heart Failure and Intramural Thrombus. Yangtze Medicine, 3, 64-71.

https://doi.org/10.4236/ym.2019.31007

Received: October 16, 2018

Accepted: March 19, 2019

Published: March 22, 2019

Copyright $\odot 2019$ by author(s) and Scientific Research Publishing Inc. This work is licensed under the Creative Commons Attribution International License (CC BY 4.0).

http://creativecommons.org/licenses/by/4.0/

\begin{abstract}
Isolated left ventricular non-compaction is recently described as a rare form of cardiomyopathy that is associated with a heart failure, life threatening cardiac arrhythmia and thromboembolic complications. The diagnosis is based on echocardiography demonstration of spongy myocardium. Here we report a case of 74 years old female patient diagnosed as an isolated left ventricular non-compaction with congestive heart failure, intramural thrombus and hypertension. There is no specific treatment for LVNC; therapeutic measures are directed towards the patient's symptom (heart failure, arrhythmia and thrombotic events) and consideration of an implantable cardioverter defibrillator and cardiac transplantation.
\end{abstract}

\section{Keywords}

Left Ventricular Non-Compaction, Cardiomyopathy, Heart Failure, Arrhythmia, Heart Transplantation

\section{Introduction}

Left ventricle non-compaction (LVNC) is a recently described cardiomyopathy which is often familial and autosomal dominant and characterized by presence of excessively prominent trabeculations and deep intertrabecular recesses [1] [2]. Both familial and sporadic forms of non-compaction have been described, the prevalence being estimated to be between $0.01 \%-0.27 \%$ [3]. LVNC was recently suggested to represent the third most commonly diagnosed cardiomyopathy [4] and included in the 2006 classification of cardiomyopathy as a genetic cardi- 
omyopathy. The most frequently involved sites are left ventricle apex and inferior wall, and involvement of other left ventricle walls and right ventricle has also been reported. Clinical manifestations can range from no symptom to progressive deterioration in cardiac function such as congestive heart failure seen in $30 \%-70 \%$ of cases, systemic thromboembolic event occurring in $7 \%-38 \%$, and stroke [4]. Left ventricle systolic dysfunction is due to subendocardial hypoperfusion, microcirculation dysfunctions and diastolic dysfunctions. Cardiac arrhythmias can occur including ventricular and supraventricular tachycardia as well as atrial fibrillation. These disorders can lead to syncope and sudden cardiac death in up to $18 \%$ of the patients in observed populations [5].

LVNC is diagnosed using Doppler echocardiography with the presence of thin (compacted) epicardium with thick, spongy endocardial (non-compacted) surface and numerous prominent hypertrabeculation and multiple intertrabecular recesses perfused from ventricular cavity. A valid diagnosis can be made when the non-compacted to compacted layer ratio is higher than 2 at the end of diastole or at the end of systole [2]. Cardiac Magnetic Resonances Imaging is the best imaging modality for the diagnosis of non-compaction of ventricle and gives detail information regarding the extent of non-compaction and supplemental morphological information [6].

\section{Case Presentation}

A 74 years old female patient with known case of hypertension for 4 years under medications was transferred from local hospital to our hospital in emergency department with chief complain of syncope attack since two week, 3 - 5 episodes per day, and she don't know, how long having a fainting attack with one month history of progressive exertional breathlessness and shortness of breath is more several during supine position and in night time. There is no history of smoking and alcohol intake in past. On examination she was in sinus rhythm with pulse rates was 58 beats/minute, blood pressure was $160 / 70 \mathrm{~mm} \mathrm{Hg}$, respiratory rate was 20 times per minute and temperature were $98.8^{\circ} \mathrm{F}$. On local examination, she has bilateral pitting edema and on systemic examination, she has a basal crepations on both sides of the lungs.

On laboratory investigation total Red blood cell counts was 4.8 millions $/ \mathrm{mm}^{3}$ (Normal range: 4.5 - $5.5 \mathrm{million} / \mathrm{mm}^{3}$ ), Total white blood cells count was 8 thousand $/ \mathrm{mm}^{3}$ (Normal range: $4-11$ thousand $/ \mathrm{mm}^{3}$ ), Total platelet count was $2.5 \mathrm{lakh} / \mathrm{mm}^{3}$ (Normal range: 1.5 - $3 \mathrm{lakh} / \mathrm{mm}^{3}$ ), Random blood sugar was 90 $\mathrm{mg} / \mathrm{dl}$ (Normal range: $70-110 \mathrm{mg} / \mathrm{dl}$ ), Blood urea was $15 \mathrm{mg} / \mathrm{dl}$ (normal range: $10-50 \mathrm{mg} / \mathrm{dl}$ ), serum creatine was $1.2 \mathrm{mg} / \mathrm{dl}$ (Normal range: $0.5-1.5 \mathrm{mg} / \mathrm{dl}$ ), sodium was $142 \mathrm{mmol} /$ litre (normal range: $135-145 \mathrm{mmol} /$ litre), potassium was $4.2 \mathrm{mmol} /$ litre (normal range: 3.5 - $5.5 \mathrm{mmol} / \mathrm{litre}$ ), CK-MB was $11 \mathrm{IU} / \mathrm{L}$ (Normal range: 5 - $25 \mathrm{IU} / \mathrm{L}$ ), Troponin-I was $0.02 \mathrm{ng} / \mathrm{ml}$ (Normal range: $<0.04$ $\mathrm{ng} / \mathrm{ml}$ ), Brain natriuretic peptide was $839.40 \mathrm{pg} / \mathrm{ml}$ (Normal range: $<300 \mathrm{pg} / \mathrm{ml}$ ) and thyroid function test is within normal limit. On Electrocardiogram finding, 
there is normal sinus rhythm with left ventricular hypertrophy (shown in Figure 1) Chest $X$-rays show cardiomegaly with small bilateral pleural effusions (shown in Figure 2). Echocardiogram show enlarged and dilated left ventricle (shown in Figure 3) with severe end diastolic dysfunction. Left ventricular ejection fraction is about $35 \%$. There are trabeculations and deep intertrabecular recesses in apical portion of left ventricle with multiple thrombi within the trabeculations.

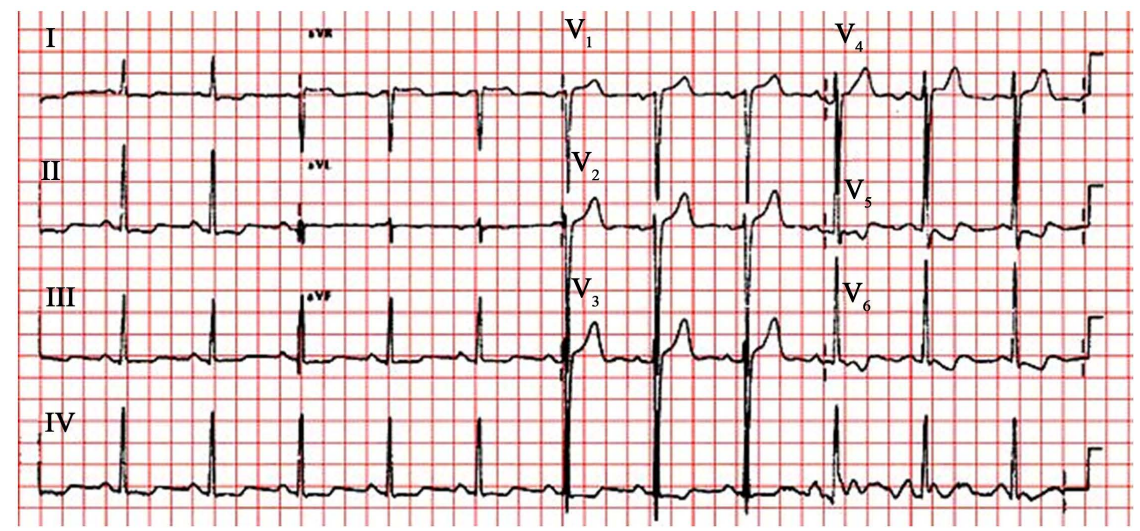

Figure 1. The 12 lead resting electrocardiogram (ECG) showing normal sinus rhythm with left ventricular hypertrophy (is tall R-wave in V6/V5 and tall S-wave inV1/V2) with normal QT intervals.

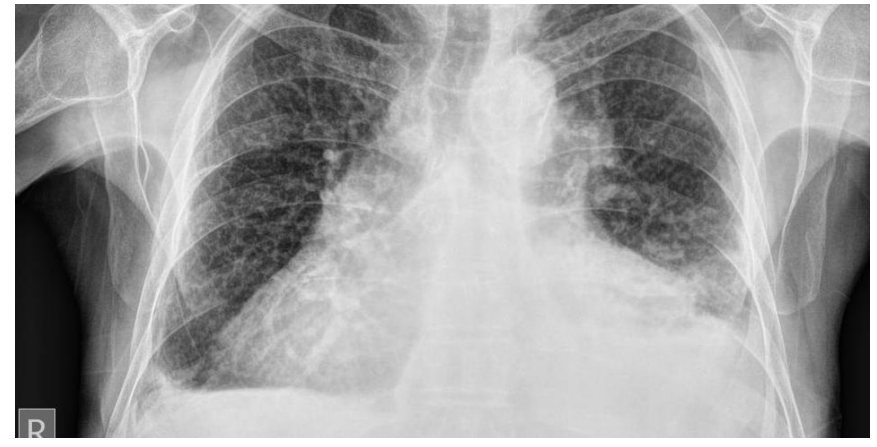

Figure 2. Chest X-ray showing cardiomegaly with bilateral pleural effusion.
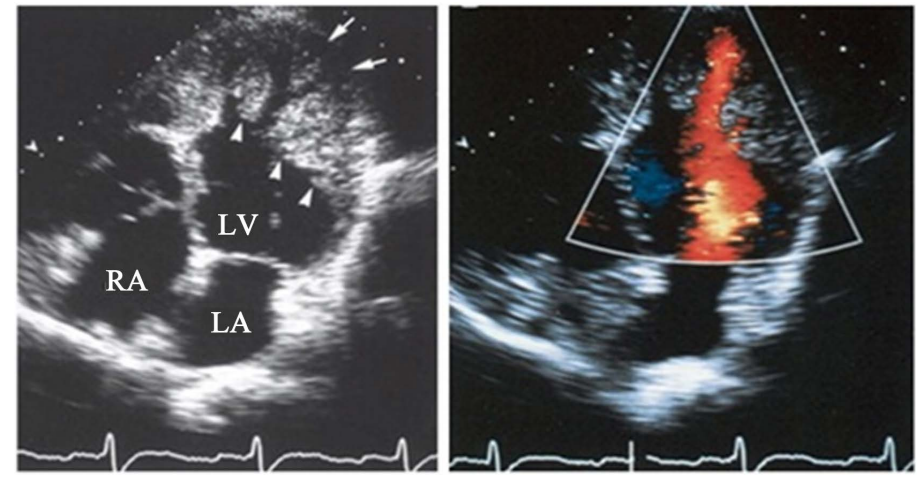

Figure 3. Echocardiography, apical four chamber views showing trabeculations in left ventricular apex (arrow) myocardium with multiple thrombi within the left ventricle and LVH. RA (right atrium), LA (Left atrium), LV (left ventricle), RV (right ventricle). 
Medical therapy was started with diuretics (Furosemide $40 \mathrm{mg}$ daily), Angiotensin converting enzyme inhibitors, beta blockers (Carvedilol), and Digoxin for the management of heart failure and intravenous heparin anticoagulation for left ventricular thrombi and subsequently changes to oral warfarin. The patient showed clinical improvement and discharged after 10 days of hospital admission in oral medications.

\section{Discussion}

LVNC is a myocardial disease with genetic basis that may result in heart failure, arrhythmia, thromboembolism, sudden cardiac death and characterized by presence of excessive and prominent trabeculations along with deep recesses that communicate with ventricular cavity [7] (shown in Figure 4). There is a male preponderance $56 \%-82 \%$ of total cases and age groups is highly variable, case has been reported in infants as well as in the elderly [8]. LVNC has been reported to account for approximately $9 \%$ of all forms of primary childhood cardiomyopathy. In the most recent American heart association classification, LVNC was listed as a primary cardiomyopathy with genetic origin. Adults are known to have severe disease and higher mortality in comparison to children. LVNC was an isolated finding in $74 \%$ cases. Non-compaction ventricular myocardium involved only the left ventricle in $62 \%$ of the patients and both ventricles in $38 \%$. LVNC is sometimes associated with other congenital cardiac condition such as atrial septal defects, congenital aortic stenosis and coarctation of the aorta [9].

The aetiology of left ventricular non-compaction is largely unknown but believed due to disturbance in compaction of myocardium during embryogenesis in fetal life between 5 and 10 weeks of gestation [3]. Left ventricular non-compaction is generally autosomal dominant inheritance. At least nine genes have been reported in patient with LVNC including genes encoding LIM domain binding
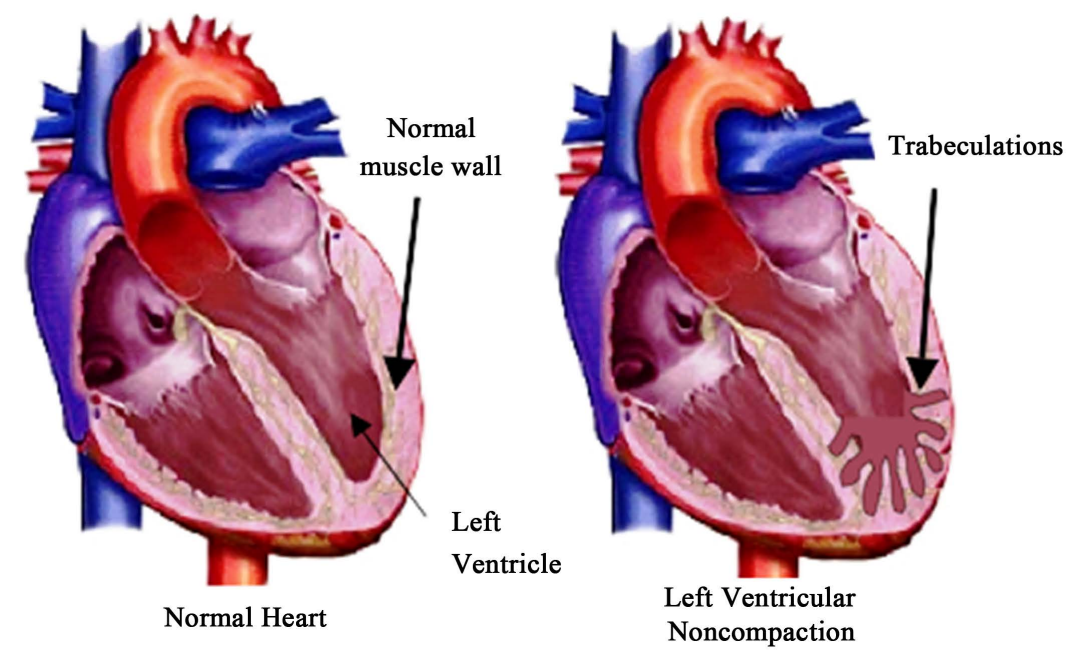

Figure 4. Diagram showing multiple deep trabeculations (multiple fingers like projection) in the muscle wall of Left ventricle in LVNC [12]. 
protein 3, alpha-dystrobrenin, tafazzin, lamin $\mathrm{A} / \mathrm{C}, \beta$-myosin heavy chain, alpha-cardiac actin, cardiac Troponin T, SCN5A, and tropomyosin I [10]. There is some evidence of an acquired form of LVNC in adults in compensatory response to an impaired myocardium [11], such cases have been reported in conjunction with other disease like neuromuscular dystrophy.

Ventricular tachyarrhythmias are reported in approximately in $47 \%$ patients and sudden cardiac death in all most half of them in adult populations [13]. Ventricular arrhythmia secondary to left ventricular non compaction is usually resistant to antiarrhythmic drug therapy. Adults are known to have severe disease and higher mortality in comparison to children [14]. Left ventricular systolic dysfunction, rhythm disturbance and presence of blood in the deep intertrabecular recesses contribute to intraventricular thrombus formation [14].

ECG abnormalities are seen in majority of patient with LVNC, ranging from left ventricular hypertrophy and repolarisation changes to inverted $\mathrm{T}$-waves, non-specific ST changes, AV block and intraventricular conduction abnormalities [2]. Echocardiography remains the reference standard for the diagnosis of Left ventricular non-compaction and echocardiography criteria for diagnosis of isolated left ventricular non-compaction is shown in Table 1 [15]. Cardiac magnetic resonance imaging also used for the diagnosis of LVNC in individual, where image quality at echocardiography is limited. In contrast to echocardiography, with cardiac magnetic resonance imaging the ratio of non-compacted to compacted myocardium should be measured during diastole, a ratio of greater than 2.3:1 confirming pathological trabeculations of the left ventricle and Cardiac MRI criteria shown in Table 2 [16].

Table 1. Echocardiography criteria for the diagnosis of isolated LVNC [15].

Following are the Echocardiography criteria for the diagnosis of left ventricular non-compaction:

- Presence of multiple echocardio-graphic trabeculations, particularly in apex and free wall of left ventricle.

- Multiple deep intertrabecular recesses communicating with ventricular cavity, as demonstrated by colour Doppler imaging.

- A two layered structure of the endomyocardium with a ratio of end-systolic non-compacted endocardial layer to compacted layer of $>2.0$ in adult or $>1.4$ in children.

- Absence of other congenital or acquired heart disease, particularly those causing left ventricular outflow obstruction.

Table 2. Cardiac MRI criteria for the diagnosis of isolated LVNC [16].

Following are the cardiac MRI criteria for the diagnosis of isolated LVNC:

- The ratio of no-compacted myocardium to compacted myocardium must be greater than 2.3:1 during diastole.

- A trabeculations left ventricular mass above $20 \%$ of total mass. 
Management of LVNC is mainly focus on control of symptom and prevention of complications. Standard treatment of systolic and diastolic heart failure is recommended for patient with LVNC and heart failure. Heart failure is managed by Angiotensin converting enzyme inhibitors or Angiotensin receptors blockers, beta blockers mainly carvedilol, Diuretics and Digoxin. Beta blockers mainly Carvedilol improved left ventricular function, mass and neurohormonal dysfunction [17]. There is a risk of thrombus formation, so give anticoagulation therapy (warfarin or Acenocoumaral) in patient with impaired systolic functions $(\mathrm{LVEF}<40 \%)$ for the prevention of thromboembolism. Implantable defibrillators are recommended for the primary prevention of sudden cardiac death in patient with severe left ventricular systolic dysfunction. Biventricular pacing is recommended in patient with severe left ventricular systolic dysfunction and symptomatic heart failure [9]. In refractory cases with dilated cardiomyopathy, cardiac transplantation is option of treatment.

In our case, with pharmacological therapy for heart failure, there was marked improvement in patient symptomatic status (New York heart association functional class II) and left ventricular systolic dysfunction was improved (LVEF $\geq$ $40 \%)$. Hence she didn't fulfill the current guidelines for the implantation of cardiac resynchronization therapy (LVEF $\leq 35 \%$, NYHA functional class III or more, optimal tolerated medical therapy and. QRS duration > $120 \mathrm{~ms}$ ) [18]. Thus she didn't receive biventricular automatic intracardiac defibrillator.

The prognosis of LVNC is poor and larger left ventricular end-systolic diameter at initial presentation, NYHA class III/IV heart failure; chronic atrial fibrillation and presence of left bundle branch block are markers of poor prognosis [1]. About $47 \%-60 \%$ of adults died due to ventricular tachycardia, ventricular fibrillation, stroke and pulmonary edema or undergoes cardiac transplantation within 4 - 6 years [1]. LVNC patient should be screened annually with 24 hours electrocardiography recording.

\section{Learning Point}

- There is a strong familial occurrence, so all first degree relatives are recommended to have screening with echocardiography.

- Despite of being a rare condition, LVNC is being recognised more frequently than before due to increased awareness about its natural history, clinical manifestations and improved modalities of cardiac imaging.

- If not recognised early, LVNC can present with fatal arrhythmias, systemic embolism and sudden cardiac death, which can lead to significant morbidity and mortality. It is important to physicians to recognize this condition for successful treatment.

\section{Conclusion}

Isolated left ventricular non-compaction is a rare but important form of cardiomyopathy that should not be overlooked in patient presenting with cardiac failures. A high index of suspicion for non-compaction is necessary as the condi- 
tion may lead to serious heart failure, thromboembolic events, ventricular arrhythmias or sudden cardiac death. Early recognition of non-compaction may give better follow up and management of patient with this condition. A ratio of non-compacted to compacted wall greater than 3 and involvement of three or more segments are signs of poor prognosis. Echocardiography is diagnostic cornerstone. Treatment should direct towards prevention and management of heart failure, ventricular arrhythmia and prevention of thromboembolic events. The long term prognosis of non-compaction is poor.

\section{Acknowledgements}

This case reporting is supported by the National Natural Science Foundation of China (31700736), Hubei Province Natural Science Foundation of China (2016CFB180), Hubei Province Health and Family Planning Scientific Research Project (WJ2016Y07), Hubei Province Scientific and Technological Research Project (Q20171306), Jingzhou Science and Technology Development Planning Project (JZKJ15063) and the Yangtze Fund for Youth Teams of Science and Technology Innovation (2016CQT04).

\section{Consent}

Written informed consent was obtained from the patient for publication of this case report and accompanying images. A copy of the written consent is available for review by Editors in chief of this journal.

\section{Conflicts of Interest}

The authors declare no conflicts of interest regarding the publication of this paper.

\section{References}

[1] Oechslin, E.N., et al. (2000) Long-Term Follow-Up of 34 Adults with Isolated Left Ventricular Noncompaction: A Distinct Cardiomyopathy with Poor Prognosis. Journal of the American College of Cardiology, 36, 493-500. https://doi.org/10.1016/S0735-1097(00)00755-5

[2] Weiford, B.C., Subbarao, V.D. and Mulhern, K.M. (2004) Noncompaction of the Ventricular Myocardium. Circulation, 109, 2965-2971. https://doi.org/10.1161/01.CIR.0000132478.60674.D0

[3] Finsterer, J. (2010) Left Ventricular Non-Compaction and Its Cardiac and Neurologic Implications. Heart Failure Reviews, 15, 589-603. tps://doi.org/10.1007/s10741-010-9175-5

[4] Towbin, J.A., Lorts, A. and Jefferies, J.L. (2015) Left Ventricular Non-Compaction Cardiomyopathy. Lancet, 386, 813-825. https://doi.org/10.1016/S0140-6736(14)61282-4

[5] Ritter, M., et al. (1997) Isolated Noncompaction of the Myocardium in Adults. Mayo Clinic Proceedings, 72, 26-31. https://doi.org/10.4065/72.1.26

[6] Thuny, F., et al. (2010) Assessment of Left Ventricular Non-Compaction in Adults: Side-by-Side Comparison of Cardiac Magnetic Resonance Imaging with Echocardiography. Archives of Cardiovascular Diseases, 103, 150-159. 
https://doi.org/10.1016/j.acvd.2010.01.002

[7] Chin, T.K., et al. (1990) Isolated Noncompaction of Left Ventricular Myocardium. A Study of Eight Cases. Circulation, 82, 507-513. https://doi.org/10.1161/01.CIR.82.2.507

[8] Ichida, F. (2009) Left Ventricular Noncompaction. Circulation Journal, 73, 19-26. https://doi.org/10.1253/circj.CJ-08-0995

[9] Pantazis, A.A. and Elliott, P.M. (2009) Left Ventricular Noncompaction. Current Opinion in Cardiology, 24, 209-213. https://doi.org/10.1097/HCO.0b013e32832a11e7

[10] Xing, Y., et al. (2006) Genetic Analysis in Patients with Left Ventricular Noncompaction and Evidence for Genetic Heterogeneity. Molecular Genetics and Metabolism, 88, 71-77. https://doi.org/10.1016/j.ymgme.2005.11.009

[11] Hutchins, I.M. and Schaefer, S. (2012) Progressive Left Ventricular Noncompaction and Systolic Dysfunction. Experimental \& Clinical Cardiology, 17, 81-83.

[12] Arbustini, E., Weidemann, F. and Hall, J.L. (2014) Left Ventricular Noncompaction: a Distinct Cardiomyopathy or a Trait Shared by Different Cardiac Diseases? Journal of the American College of Cardiology, 64, 1840-1850. https://doi.org/10.1016/j.jacc.2014.08.030

[13] Brescia, S.T., et al. (2013) Mortality and Sudden Death in Pediatric Left Ventricular Noncompaction in a Tertiary Referral Center. Circulation, 127, 2202-2208. https://doi.org/10.1161/CIRCULATIONAHA.113.002511

[14] Suvarna, J.C., Deshmukh, C.T. and Hajela, S.A. (2009) Left Ventricular Noncompaction: A Cardiomyopathy Often Mistaken. Indian Journal of Medical Sciences, 63, 303-307. https://doi.org/10.4103/0019-5359.55119

[15] Jenni, R., Oechslin, E.N. and van der Loo, B. (2007) Isolated Ventricular Non-Compaction of the Myocardium in Adults. Heart, 93, 11-15. https://doi.org/10.1136/hrt.2005.082271

[16] Petersen, S.E., et al. (2005) Left Ventricular Non-Compaction: Insights from Cardiovascular Magnetic Resonance Imaging. Journal of the American College of Cardiology, 46, 101-105. https://doi.org/10.1016/j.jacc.2005.03.045

[17] Toyono, M., et al. (2001) Effects of Carvedilol on Left Ventricular Function, Mass, and Scintigraphic Findings in Isolated Left Ventricular Non-Compaction. Heart, 86, E4. https://doi.org/10.1136/heart.86.1.e4

[18] Epstein, A.E., et al. (2013) 2012 ACCF/AHA/HRS Focused Update Incorporated into the ACCF/AHA/HRS 2008 Guidelines for Device-Based Therapy Of Cardiac Rhythm Abnormalities: A Report of the American College of Cardiology Foundation/American Heart Association Task Force on Practice Guidelines and the Heart Rhythm Society. Journal of the American College of Cardiology, 61, e6-75. https://doi.org/10.1161/CIR.0b013e318276ce9b

\section{Abbreviations}

LVNC: Left ventricular non-compaction.

NYHA: New York heart association.

LVEF: left ventricular ejection fraction.

SCD: Sudden cardiac death.

LVH: left ventricular hypertrophy. 